\title{
Aneurysmal Bone Cyst of the Skull
}

\author{
N.O. Ameli, K. Abbassioun, A. Azod and H. Saleh
}

\begin{abstract}
Aneurysmal bone cysts rarely affect the skull. Thirty-six cases including four reported in this paper are reviewed. The condition usually affects children and young adults and progresses rapidly. It may result in raised intracranial or intraorbital pressure. Complete excision of the mass is the treatment of choice, but if not feasible curettage followed by low dose radiotherapy is effective. As the prognosis in this condition is good, prompt diagnosis and early treatment are of utmost importance.
\end{abstract}

RÉSUMÉ: Le kyste osseux anévrysmal affecte rarement le crâne. Notre travail a porté sur trente-six (36) cas, dont quatre (4) observations personnelles. L'affection touche le plus souvent l'enfant et le jeune adulte et progresse rapidement; elle peut entrainer une élévation de la pression intra-crânienne ou intra-orbitaire. Le traitement de choix est l'exérèse complète de la masse. Lorsque celle-ci s'avère impossible, un curetage suivi de radiothérapie à faibles doses est efficace. La précocité du diagnostic et du traitement est de la plus haute importante, d'autant plus que le pronostic de cette affection est favorable.

Can. J. Neurol. Sci. 1984: 11:466-47I

Aneurysmal bone cyst $(\mathrm{ABC})$ as a clinical entity was first described by Jaffe and Lichtenstein in 1942. Complete description of the condition appeared in 1950. Previously these cases were diagnosed as ossifying subperiosteal haematoma, subperiosteal giant cell tumour, aneurysmal giant cell tumour, benign bone aneurysm and atypical giant cell tumour.

$\mathrm{ABC}$ may occur in any part of the skeleton. Long bones and vertebrae are the most common sites, and the skull is rarely affected $(2.5-6 \%)$. The affected bone becomes expanded and ballooned with many communicating cavities containing venous blood. Although most of the spaces are filled with unclotted venous blood under great pressure, some may contain sanguinous or even clear fluid. The walls of these spaces are lined by an indistinct epithelium and the stroma consists of a brownish fibro-osseous matrix which microscopically shows giant cell reaction with hemosiderin laden macrophages, extravasated blood, and fields of osteoid and new bone formation (Lichtenstein, 1950).

ABC usually affects the young, 90 percent being less than 20 years of age. It grows rapidly. When the skull is affected, signs and symptoms are related to location of the lesion.

In this paper we describe four cases of $\mathrm{ABC}$ of the skull seen by us in the last 25 years. Case 1 has been previously reported.

\section{CASE RePORTS}

Case 1: A 13-year-old girl was admitted complaining of headaches of six weeks duration. Soon after the headaches started she noticed a lump on the left side of the head, which grew steadily larger. There was a history of trauma to the same side of the head at four years of age. On examination, a tender mass in the left posterior frontal region measured $7 \times 12 \mathrm{~cm}$. The overlying scalp was not involved, and there was no abnormal vascularity. Neurologic and funduscopic examination was normal. Radiographs of the skull showed an expansile mass in the left frontal region with increased density of the surrounding bone. Carotid angiography was normal. The mass was removed in one piece and the bone defect repaired by split-rib cranioplasty. Five years later there was no recurrence of the lesion.

Case 2: A girl aged 16 years developed right exophthalmos three months before admission, which had grown rapidly. Proptosis of the eye measured $10 \mathrm{~mm}$; the globe was pushed directly forward and the

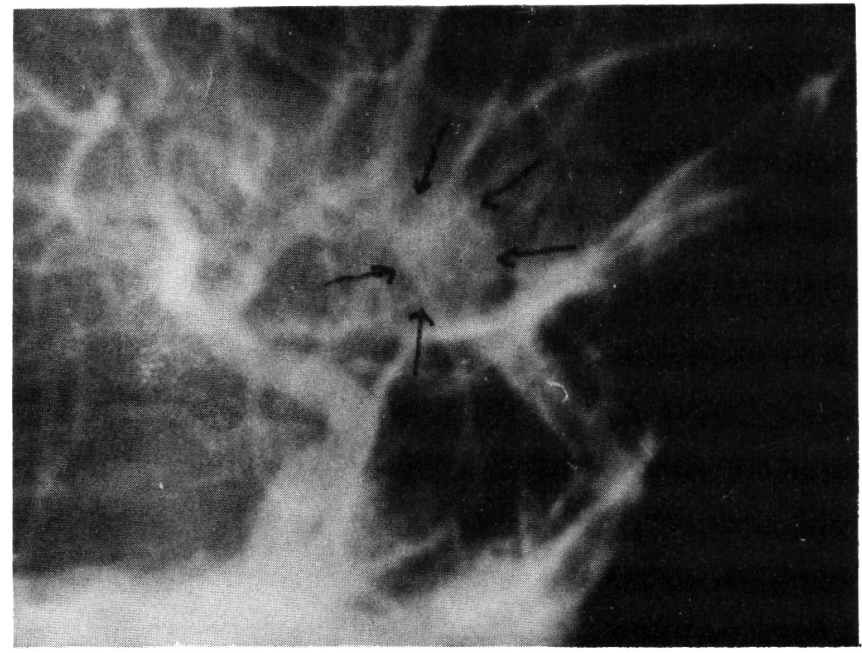

Figure 1-Angiogram of Case 2 demonstrating a round vascular mass. 


\section{Table 1: Cinical Summary of 36 Cases of Aneurysmal Bone Cyst of the Skull}

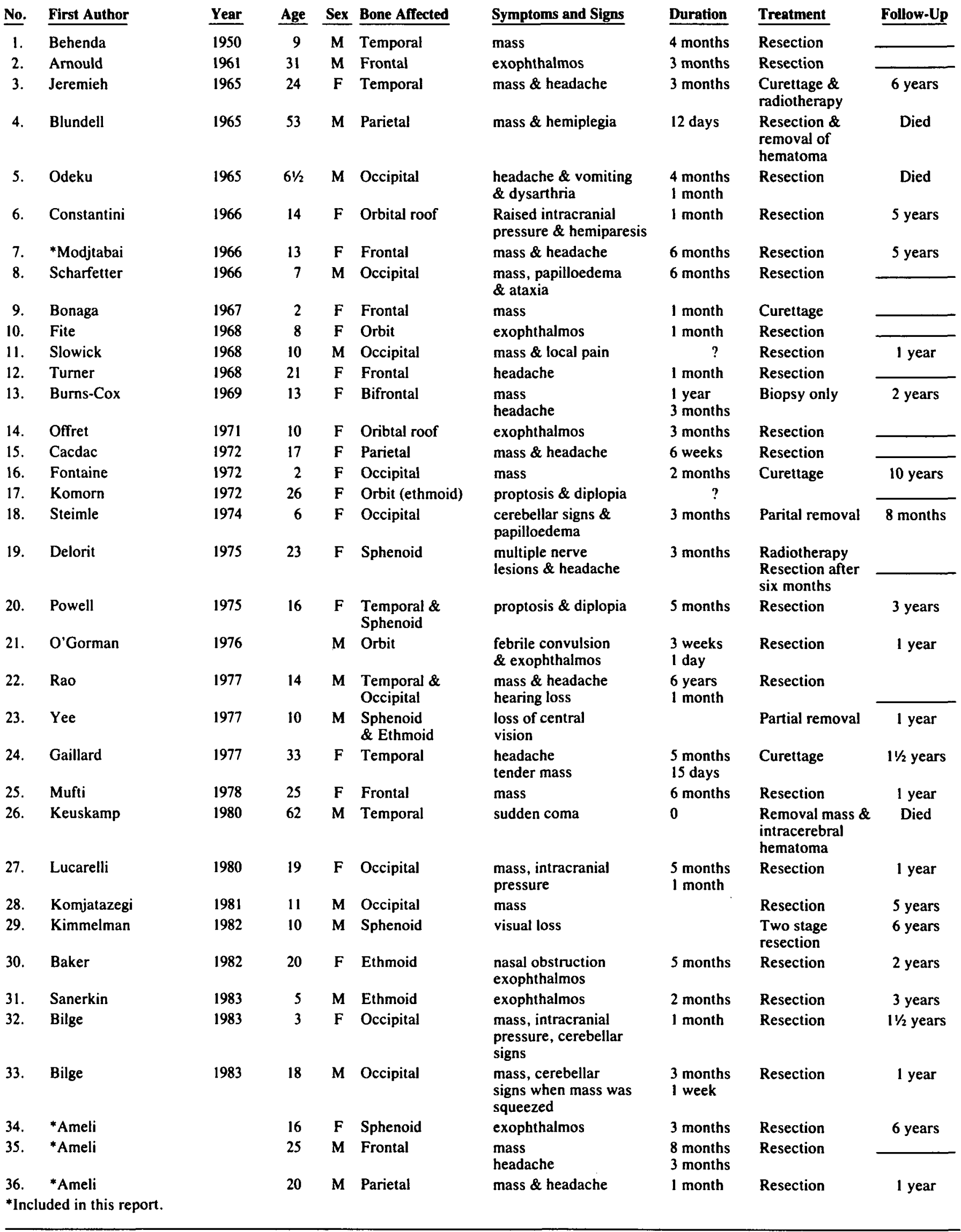




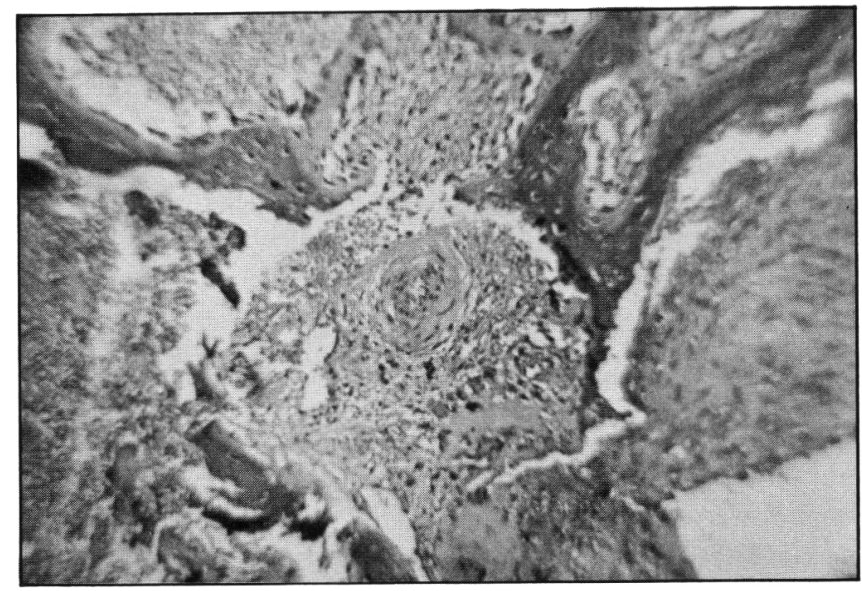

Figure 2 - Histology of Case 2 demonstrating vascular spaces with fibroosseous matrix, hemosiderin-laden phagocytes and few giant cells.

upper lid was oedematous. Visual acuity and fields were normal, but the veins in the right fundus were engorged. Radiographs of the skull showed some irregularity of the superior surface of the right orbital roof. Right carotid angiography demonstrated a round vascular mass 12 $\mathrm{mm}$ in diameter, above the medial part of the sphenoidal wing (Fig. 1). The orbital roof was removed through a right frontal flap. The dura was then opened and the frontal lobe was retracted upwards and backwards to expose a small reddish granulomatous mass anterior to the carotid artery and lateral to the optic nerve. The mass was adherent to the dura and the underlying bone. After ligating a few feeding vessels it was removed piecemeal and the dural bed was thoroughly cauterised. Three months after surgery there was no evidence of the exophthalmos or the edema of the lid, and six years later there was still no evidence of recurrence. Histological examination of the lesion showed vascular spaces with a mesh of fibrous and osseous tissue, and numerous hemosiderin-laden histiocytes and a few giant cells (Fig. 2).

Case 3: A man aged 25 years noticed a small tender mass on the right side of his forehead eight months before admission. In the last three months it had rapidly increased in size. He also complained of right sided frontal headache. There was no history of trauma. On examination there was a hard bony mass measuring $5 \mathrm{~cm}$. in diameter in the right frontal bone. The overlying scalp was normal. Radiographs of the skull showed an expansile lesion with sclerosis of the surrounding bone. At operation the mass was completely excised and the bone defect was repaired by split-rib cranioplasty. Histology of the lesion was typical of $\mathrm{ABC}$. We have not been able to follow up this case.

Case 4: A man aged 20 years had a motorcycle accident with head injury three months before admission. Two months after this accident he noticed a tender mass at the back of his head which grew rapidly. He was also complaining of attacks of generalised headaches. On examination there was a large tender mass in the left posterior parietal region. The overlying scalp was normal. There was no abnormality in the central nervous system, and no papilledema. Routine chest $x$-rays, blood and urine tests were all normal. Radiographs of the skull showed an expansile lesion in the posterior part of the left parietal bone with most of the expansion outward. The outer wall was thin and there were many trabeculae (Fig. 3). CT scan with enhariement showed a dense mass with a small cavity containing a fluid of lower density than blood (Fig. 4). At operation the mass was completely removed and the defect repaired with acrylic cranioplasty. There was no recurrence of the lesion when the patient was seen a year later. The histological diagnosis confirmed $A B C$.

\section{Analysis of 36 Case of ABC of The SKull}

In addition to our four cases we were able to find 32 other cases with sufficient data for analysis in the literature (Table 1). The youngest patient was 14 months old and the oldest was 62 years, but there were only four cases older than 30 years. The

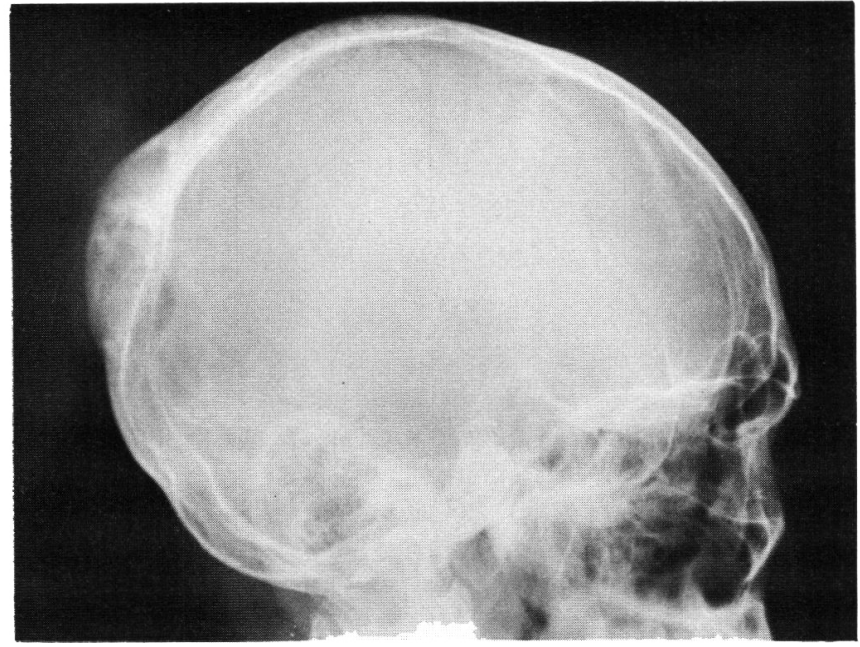

Figure 3 - Radiograph of case 4 shows an expansile mass with a number of small cystic cavities. Most of the expansion is outward.

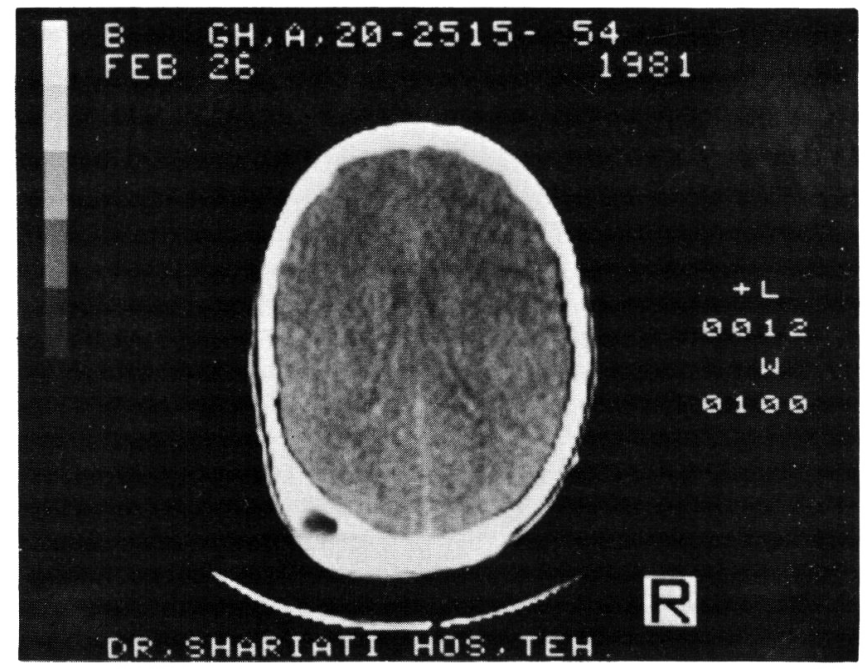

Figure 4-CT scan (with enhancement) of case 4, shows a dense lesion of the bone extending beyond the midline with one small cavity containing low density fluid.

age distribution is shown in Fig. 5. There were 16 males and 20 females. Age and sex distribution closely correspond with ABC of the other bones of the skeleton. Frontal bone was affected in six cases, temporal in 5 , parietal in 3 , occipital in 9 and the base of the skull and orbital bones in 13 cases. In 34 cases the lesion was extradural and in 2 cases (26 and 32 ) intradural. It is possible that in these two cases the lesion was subperiosteal and secondarily had invaded the dura. In both cases the mass was adherent to the bone. The rate of growth was rapid in nearly all the cases. If case 22 with large occipital mass growing for six years before admission is excluded, the average duration of symptoms in the other 35 cases was 3 months. It appears that in the older age group the condition may progress even more rapidly. Case 4 , a 53 year old man noticed a small lump on his head twelve days before admission which grew to a mass measuring $5 \times 10 \mathrm{~cm}$. in that interval. Case 26 a man aged 62 suddenly became comatose with signs of cerebral herniation. At operation an intracerebral haematoma arising from an intradural 


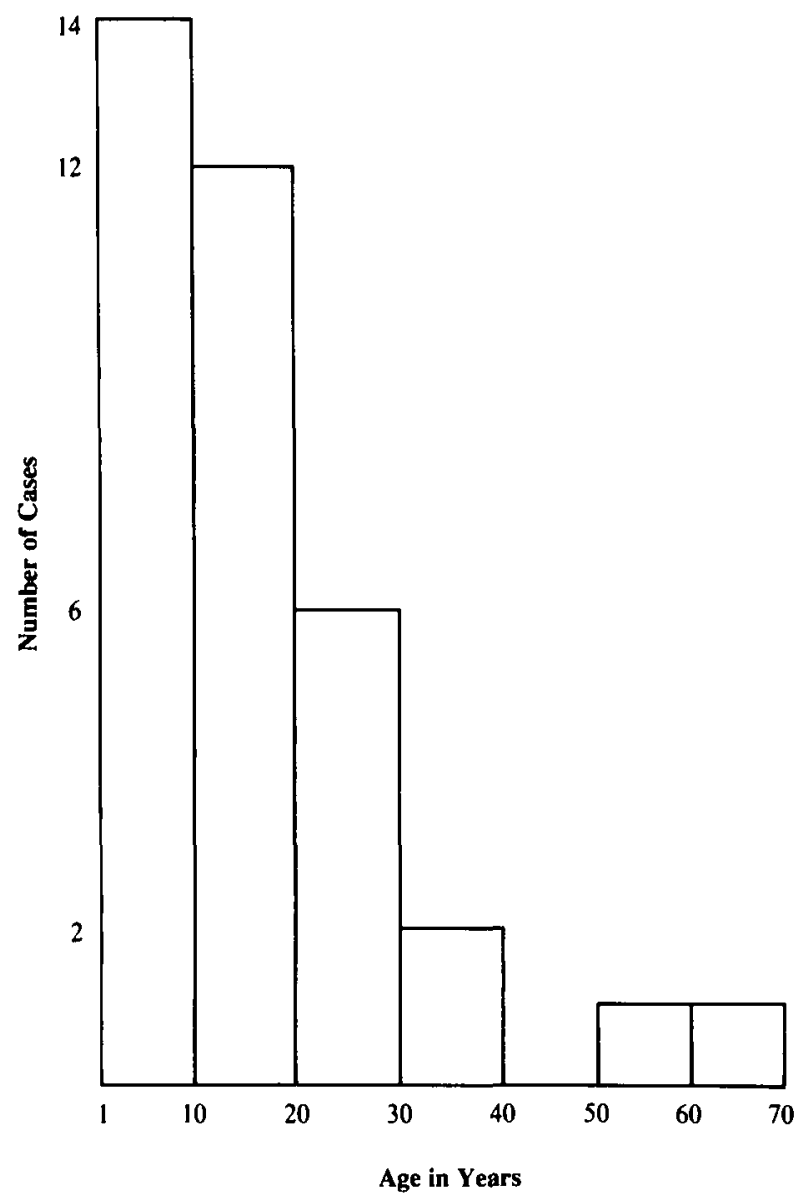

Figure 5-Age distribution of 36 cases of $A B C$ of the skull.

ABC was found. Both these patients died following surgery.

Signs and symptoms of $A B C$ of the skull depend on its location and rate of growth. Those affecting the vault do not seem to produce an intracranial mass of significant size, but they give rise to focal and generalised headaches, and the mass is usually tender to palpation. The overlying scalp is not involved and there is no increased vascularity or bruit on auscultation.

In eight cases with raised intracranial pressure the lesion was either in the basal part of the occipital bone or the base of the skull. We have noted the same phenomenon in monostotic fibrous dysplasia which affects the same age group (Ameli et al., 1981).

Proptosis was the presenting symptom in nine cases, demonstrating that $\mathrm{ABC}$ should be considered as a possible diagnosis in rapidly developing unilateral exophthalmos in young patients. An erroneous diagnosis of a malignant lesion in these patients, who may then be subjected to large doses of radiotherapy, may prove disastrous.

Cranial nerves were involved in three cases: the optic nerve was involved in a lesion of the sphenoidal sinus, the eighth nerve in a lesion of the temporal bone, and multiple nerves in a lesion of the sphenoidal sinus.

Methods of investigation consisted of plain radiographs, angiography, isotope scanning in at least two cases, and CT scan since the introduction of this technique, in three cases. In most cases the definite diagnosis was made by histological examination of the specimens.
Treatment varied from biopsy alone in one case to complete excision of the mass in 28 cases. Four cases were treated by currettage, two by radiotherapy, and two other cases radiotherapy after currettage, in one case resection of the mass was achieved six months after a course of radiotherapy and finally one case was treated by partial removal of the lesion.

Three cases died following the operation. Cases 4 and 26 have already been discussed and case 5 was a $61 / 2$ year old boy with a huge occipital mass.

Follow-up had been mentioned in 21 cases, and it ranged from 8 months to 10 years. The longest follow up was 10 years in case 14 who had been treated by currettage alone. There had been no report of recurrence in any of the cases of $A B C$ of the skull, although this is not rare when curettage has been the method of treatment in other bones of the skeleton.

\section{Discussion}

Pathogenesis of ABC is still obscure. According to Lichtenstein (1950) "the condition apparently results from some persistent local alteration in hemodynamics leading to increased pressure. The anomalous circulation could conceivably result from intraosseous shunts."

Jaffe (1962) believes that the cyst arises from a pre-existing pathology. $A B C$ appearing with some other lesion is not a rare occurrence, these include fibrous dysplasia, osteoclastoma, chondromyxoid fibroma, non ossifying fibroma, solitary bone cyst, cervical fusion and fracture of long bones. Bonakdarpour (1978) recognises two types of ABC, primary, and secondary to another lesion. In 75 cases he considered that 49 were primary $\mathrm{ABC}$ and 26 secondary.

Trauma is often mentioned in case histories of $A B C$ including the two of our own cases.

Some authors believe that no definite cause and effect relationship has been proved, but cases appearing after a fracture and history of case 12 suggest that at least in some patients trauma is a predisposing factor. Case 12 was a female aged 21 years who was hit by a golf ball on her forehead 9 years before admission, this caused a lump which did not completely disappear and began to grow rapidly five weeks before admission.

History of trauma in some cases, existence of other lesions in many others, rapid growth of the lesion, presence of communicating spaces filled with unclotted venous blood under great pressure and finally the young age of the majority of the patients lead us to suggest that the condition is due to development of a circulatory vicious cycle. It is possible that the affected bone had been the site of a congenital vascular anomaly such as an arteriovenous shunt or a small hemangioma. Trauma or development of another pathology produces the vicious circle causing increasingly greater pressure, this in turn causes rapid expansion of the bone. In this way we can explain why a simple curettage and even taking a biopsy may cure or arrest the progress of the lesion by breaking the cycle.

\section{Diagnosis}

When the vault is affected plain roentgenograms of the skull demonstrating an expansile lesion with trabeculae and sclerosis of the surrounding bone would suggest $A B C$, but when the base or nasal sinuses are affected diagnosis becomes much more difficult; in these cases CT scan may be valuable. Angiography of $\mathrm{ABC}$ of other parts of the skeleton have shown pathological 
circulation in the venous phase and occasionally arteriovenous shunts, but in $\mathrm{ABC}$ of skull carotid angiography has not proved of much value, probably selected external carotid angiography is needed. In two cases ( 21 and 32 ), both with rapidly progressive proptosis, carotid angiography demonstrated round vascular masses, receiving their blood supply from the internal carotid and ophthalmic arteries.

$\mathrm{ABC}$ of the skull has to be differentiated from simple bone cyst, hemangioma, meningioma, monostotic fibrous dysplasia, giant cell tumour, malignant lesions, and hydatid disease. On plain radiographs many of these conditions can be differentiated when they affect the vault. Angiography would easily demonstrate a meningioma. Monostatic fibrous dysplasia which occurs in the same age group has characteristic radiological picture, large amount of fine spongy new bone formation is seen with areas of translucency adjacent to densely calcified bone. Occasionally it appears as a solitary expansile lesion, but there are no trabeculae and the lesion grows very slowly. A case of cystic lesion of occipital bone radiologically similar to $\mathrm{ABC}$ reported by Banna et al. (1974) was probably a variant of ABC.

Malignant disease of the nasal sinuses may be difficult to differentiate, and biopsy of the lesion would be necessary to reach a correct diagnosis. Giant cell tumour appears in an older age group, as $90 \%$ of the cases being older than 20 years. Histologically it has a cellular stroma with numerous giant cells and there are no blood filled spaces; osteoid tissue and bony trabeculae are not seen unless the lesion has been treated with radiotherapy.

Hydatid disease of the skull is a rare condition which shows cystic cavities separating the two tables of the affected bone but there is no increased density of the surrounding bone; and CT scan would demonstrate the low density of the cystic fluid.

\section{Treatment}

Complete extirpation of the lesion should be undertaken if at all possible, otherwise curettage followed by radiotherapy not exceeding 2000r is recommended. Curettage may cause profuse bleeding but this can be controlled by application of gauze soaked in hydrogen peroxide (Ameli et al., 1975).

Development of sarcoma following irradation has been reported in $\mathrm{ABC}$ of other bones. In a case which was mistakenly diagnosed as a giant cell tumour and subjected to intense radiotherapy, fibrosarcoma developed at the site of the lesion (Turner et al., 1968).

Although no recurrence has been reported in $A B C$ of the skull, this is not rare in the lesions of other bones which have been treated by curettage and/or radiotherapy.

\section{REFERENCES}

Ameli NO, Rahmat H, Abbassioun K (1981) Monostotic fibrous dysplasia of the cranial brones. Report of 14 cases. Neurosurg Rev 4: 71-77.

Ameli NO, Teymoorian GA, Saleh H, Eslamdoost A (1975) Aneurysmal bone cysts of the spine. Acta Neurochir (Wien) 31 (3-4): 273.

Arnould G, Lepoire J, Tridon P, Schmitt J, Guerci O (1961) Exophthalmie unilaterale par kyste solitaire de l'orbite. Rev Otol Neurol Ophthal 33: 59-61.

Baker HL, Papsidero MJ, Batskis JG, Krause CJ (1982) Aneursymal bone cyst of the ethmoid. Head Neck Surg 5: 177-180.

Banna M, Bradley WG, Kalbag RM, Tomlinson PL (1974) Occipital bone cyst causing lower cranial nerve palsies. Can J Neurol Sci 1: 206-209.
Behenda YM, Kothar SN (1950) Aneurysmal bone cyst. A case report. Ind Med Gaz 85: 544-546.

Bilge T, Coban O, Ozden B, Turantan I, Turker K, Bahar S (1983) Aneurysmal bone cysts of the occipital bone. Surg Neurol 20: 227-230.

Blundell JE (1965) Aneursymal bone cysts. A report of six cases including a fatal case associated with a non-ossifying fibroma. J Coll Radiol Aust 9: 151-157.

Bonaga R, De Gaetani CF (1967) Considerazioni anatomocliniche su due osservazioni di cisti ossea aneurismatica. Archi "De Vechi: Anat Pathol 50: 289-310.

Bonakdarpour A, Levy WM, Register L (1978) Primary and secondary aneurysmal bone cyst, a radiological study of 75 cases. Radiology 126: 75-83.

Burns-Cox CJ, Higgins AT (1969) Aneurysmal bone cyst of the frontal bone. J Bone Joint Surg 51B: 344-345.

Cacdac MA, Malis LI, Anderson PJ (1972) Aneurysmal parietal bone cyst. Case report. J Neurosurg 37: 237-241.

Constantini FE, Iraci G, Beedetti A, Melanotte PL (1966) Aneurysmal bone cyst as an intracranial space occupying lesion. Case report. J Neurosurg 25: 205-207.

Dabezies EJ, D'Ambrosia RD, Cuinard RG, Ferguson AB (1982) Aneurysmal bone cyst after fracture. A report of three cases. J. Bone Joint Surg (Am) 64: 617-621.

Delorit GT, Summers GW (1975) Aneurysmal bone cyst of the sphenoid sinus. Trans Am Acad Ophthalmal Otolaryngol 80: 438-443.

Fite JD, Schwartz JF, Calhoun FP (1968) Aneurysmal bone cyst of the orbit. A clinicopatholigical report. Trans Am Acad Ophthalmol Otolargygol 72: 614-618.

Fontaine R, Fontaine JL, Bartier C (1972) Les kystes anévrismaux de l'os. J med Strasburg 3: (6-7) 523-533.

Gaillard J, Haguenauer JP, Damolard P, Romanet P, Patricot L (1972) Le kyst osseux anévrismal temporo-mastö̈dien à propos des images lacunaires de la voute cranienne. J Fr Otorhinolaryngol 26: 517-523.

Jaffe HL (1962) Discussion of a paper by Donaldson W.F. Aneurysmal bone cyst. J Bone Joint Surg 44: 40.

Jaffe HL, Lichtenstein L (1942) Solitary unicameral bone cyst with emphasis on Roentgen picture, patholigic appearance and the pathogenesis. Arch Surgery 44: 1004-1025.

Jeremiah BS (1965) Aneurysmal bone cyst of the temporal bone. J Int Coll Surg 43: 179-183.

Keuskamp PA, Horoupian DS, Fein JM (1980) Aneurysmal bone cyst of the temporal bone presenting as a spontaneous intracranial hemorrhage. Case report. Neurosurgery 7: 166-170.

Kimmelman CP, Posti WP, Schut L (1982) Aneurysmal bone cyst of the sphenoid in a child. Ann Otol Rhino Laryngol 9: 339-341.

Komjatszegi S (1981) Aneurysmal bone cyst of the skull. J Neurosurgery 55: 497.

Lichtenstein L (1950) Aneurysmal bone cyst. A pathological entity commonly mistaken for giant cell tumour and occasionally for hemangioma and osteogenic sarcoma. Cancer 3: 279-289.

Luccarelli G, Formari M, Savoiardo M (1980) Angiography and computerized tomography in the diagnosis of aneurysmal bone cyst of the skull. J Neurosurg 53: 113-116.

Modjtabai A, Sarkissian S, Saleh H (1966) Aneurysmal bone cyst. Report of four cases. Act Med Irani 9: 7-19.

Mufti ST (1978) Aneurysmal bone cyst of the skull. Case report. J Neurosurg 49: 730-733.

Okedu EL, Mainwaring AR (1965) Unusual aneurysmal bone cyst. A case report. J Neurosurg 22: 172-176.

O'Gorman AM, Kirkham TH (1976) Aneurysmal bone cyst of the orbit with unusual angiographic features. Am J Radiol 126: 896-899.

Offret G, Clay CL, Lecoq PJ, Arrata M (1971) Kyste anévrismal des os à localisation orbitaire. Bull Soc Ophthal France 71: 1049-1054.

Powell JO, Glaser, JS (1975) Aneurysmal bone cyst of orbit. AMA Arch Ophth 93: 340-342.

Rao KV, Rao BS, Reddy CP, Sandareshwar B, Reddy CR (1977) Aneurysmal bone cyst of the skull. Case report. J Neurosurg 47: 633-636.

Sanerkin NG, Mott MG, Roylana J (1983) "Solid" variant of aneurysmal bone cyst. An unusual intraosseous lesion with fibroblastic, osteoclastic, osteoblastic aneurysmal and fibromyxoid elements. Cancer 51: 2278-2286.

Scharfetter F (1966) Eine aneurysmatische knochenzyste des os occipital 
mit den neurologischen Zeichen eones Kleinhirntumors. Schweiz Arch Neurol Psychiatr 98: 40-47.

Slowick FA, Campbell CJ, Kettlkamp DB (1968) Aneurysmal bone cyst. An analysis of thirteen cases. J Bone Joint Surg 50A: 1142-1151.

Steimle R, Pageaut G, Tropet Y (1974) Kyste anévrismal de l'os occipital. Acta Neurochir (Wien) 30: 139-146.
Turner DA, Laird T, Bernstein LL (1968) Aneurysmal bone cyst of the calvarium. Report of a case with isotopic visualisation. Ohio State Med J 62: 1174-1176.

Yee Rd, Cogan DG, Thorp JR, Schut L (1977) Optic nerve compression due to aneurysmal bone cyst. Act Ophthalmol 95: 2176-2179. 